\title{
Performance analysis of a 7-kW crystalline silicon generator after 17 years of operation in Madrid
}

\author{
Eduardo Lorenzo , Roberto Zilles , Rodrigo Moretón ，Trinidad Gómez \\ and Ainhoa Martínez de Olcoz
}

\begin{abstract}
The degradation observed on a 7-kWp Si-x photovoltaic array after 17 years of exposure on the roof of the Solar Energy Institute of the Polytechnic University of Madrid is presented. The mean peak power degradation has been $9 \%$ over this time, or an equivalent to $0.53 \%$ per year, whereas peak power standard deviation has remained constant. The main visual defects are backsheet delamination at the polyester/polyvinyl fluoride outer interface and cracks in the terminal boxes and at the joint between the frame and the laminate. Insulation resistance complies well with the requirements of the International Electrotechnical Commission 61215 tests.
\end{abstract}

KEYWORDS

field exposure; long-term degradation; PV module performance; terminal box failures; delamination

\section{INTRODUCTION}

Publications on Si-x photovoltaic (PV) modules performance after long-term outdoor exposures are becoming increasingly available in the literature. They mainly come from dedicated test beds $[1-4]$ and as well as from PV systems in the hands of research groups [5]. Together with specialised studies [6-10], they provide useful information, helping to understand outdoor degradation mechanisms and, therefore, to improve the long-term reliability of PV modules. In summary, they show that qualification in accordance with the International Electrotechnical Commission (IEC) 61215 [11], despite not being specifically designed for measuring degradation rates but just to assure a certain robustness [12], generally encompasses peak power degradation equivalent to $0.6-1 \%$ per year for spans of around 10 to 20 years. The main observed defects are as follows: ethylene-vinyl-acetate browning, metal grid oxidation, delamination, soiling, and others. In more detail, a recent summary [13] of reported degradation rates shows an average of $0.7 \%$ per year and a median of $0.5 \%$ per year. Maximum power degradation appears to depend mainly on ultraviolet light [14], which helps to explain the differences in reported degradation rates in terms of time (per year).

This paper presents the degradation observed in a $7-\mathrm{kWp}$ Si-x PV array after 17 years of exposure on the roof of the Solar Energy Institute of the Polytechnic University of Madrid $(40.45 \mathrm{~N}, 3.72 \mathrm{~W}, 667 \mathrm{~m})$. Typical yearly meteorological data [15] of the site are as follows: horizontal global solar irradiation, $G_{\mathrm{Y}}(0)=1640 \mathrm{kWh} / \mathrm{m}^{2}$; in-plane global solar irradiation, $G_{\mathrm{Y}}(20)=1830 \mathrm{kWh} / \mathrm{m}^{2}$; average ambient temperature, $T_{\mathrm{Y}}=15^{\circ} \mathrm{C}$; and relative humidity, $H R=57 \%$. The PV array consists of 90 modules manufactured by (Málaga, Spain). Each module is made up of 60 p-type, monocrystalline silicon solar cells, textured, with a $\mathrm{TiO}_{\mathrm{X}}$ antireflection coating and interconnected with tinned copper ribbons. The cells are encapsulated with ethylene-vinyl acetate between a high transmittance flat tempered glass and a composite backsheet of Tedlar ${ }^{\circledR}$ [polyvinyl fluoride (PVF)] and polyester (PET), with a 
$\mathrm{PVF} / \mathrm{PET} / \mathrm{PVF}$ configuration. The laminate is surrounded by an anodized aluminium frame, with a silicone joint. The PV system was connected to the grid on the 13th of December 1993 by means of an inverter with galvanic insulation between the direct current and alternating current circuits, and has been kept in routine operation for around $75 \%$ of the time, whereas for the other $25 \%$, it has been used for different research purposes, mainly PV pumping testing. It can be understood here that the PV array has mostly been held at maximum power operating conditions. No particular maintenance or cleaning procedures have been made during this time. Figure 1 shows a general view of the installation and a close view of a PV module. It is worth noting the 2-cm gap between the metallic frame and the solar cells, because it has effectively avoided the impact of soiling on the energy performance and has also probably been effective in preserving electric safety.

In fact, despite significant backsheet delamination and silicon joint degradation, the PV modules have successfully passed the two electrical insulation tests (dielectric withstanding test and wet leakage test) established by the IEC 61215 [11]. As far as we know, the wet leakage insulation test results for aged PV modules have not been published before. Hence, the good insulation performance of our modules can be understood as the good news of this paper. This is particularly interesting because thermal cycles and damp heat following the IEC 61215 do not normally give rise to delamination [16], so that the associated electrical

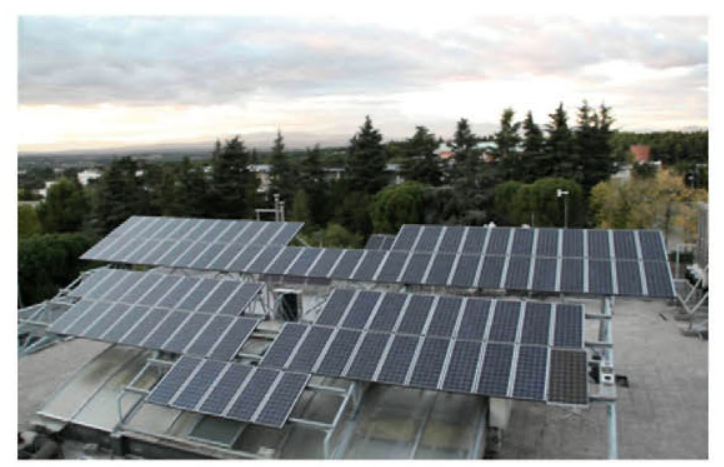

(a)

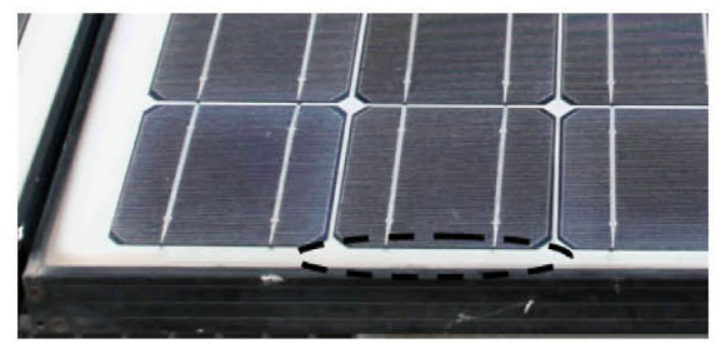

(b)

Figure 1. (a) General view of the installation. (b) Close-up view of a photovoltaic module. The 2-cm gap between the frame and the solar cells in the bottom part has effectively prevented soiling affecting the energy performance, as well as preserving the electrical insulation. safety hazard cannot be analysed on accelerated aged modules but only on naturally aged ones after many years of exposure to the elements.

In addition, electric performance degradation has been equivalent to $0.53 \%$ per year, which is along the lines of that found by other authors. Despite not being a new result, we consider that it is still valuable, because obtaining reasonably accurate degradation rates requires an interval of several years between initial and final measurements [12], and the associated difficulty makes such measurements relatively scarce.

\section{VISUAL DEFECTS}

During the first 13 years of exposure to the elements, the only visual symptom of degradation appeared in the terminal boxes. In fact, although these boxes are IP65, they are not specifically designed for PV modules but for general electric installation purposes and they include several lateral holes with their corresponding cable grips. The degradation appeared in the form of cracks at these cable grips (Figure 2). However, it should be mentioned, on the one hand, that these pieces can be easily substituted by new ones and, on the other hand, that this kind of terminal box is not used any more in the PV industry, so that further in-depth comments are not required here.

During the last 3 years, serious backsheet delamination has developed at the outer PET/PVF interface (Figure 3), affecting large areas of 62 modules, that is, $69 \%$ of the total. According to Reference [5], this indicates a stability problem in the corresponding adhesive used by the backsheet supplier. It is worth remembering that the adhesion between the polymer film (PVF) and the inorganic coating (PET) has been highlighted as a critical aspect of this technology $[2,10]$. Moreover, degradation symptoms also appeared in the joint between the laminate and the frame (Figure 4). Finally, many solar cells exhibit some colour darkening. Visual appearance suggests that this degradation is due to antireflective coating oxidation, as mentioned by other authors [5]. Table I summarises all the visual defects found and their incidence in the sample.

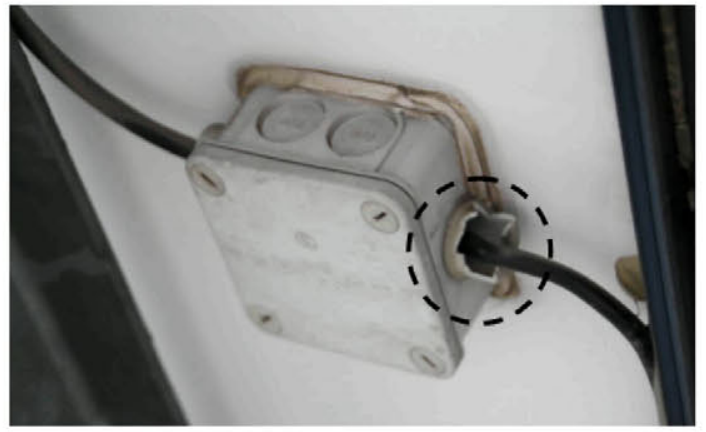

Figure 2. Cracks in the terminal boxes appeared during the first 13 years of operation. 


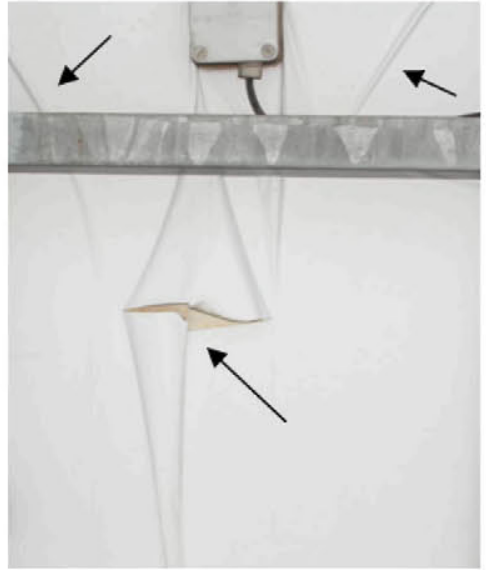

(a)

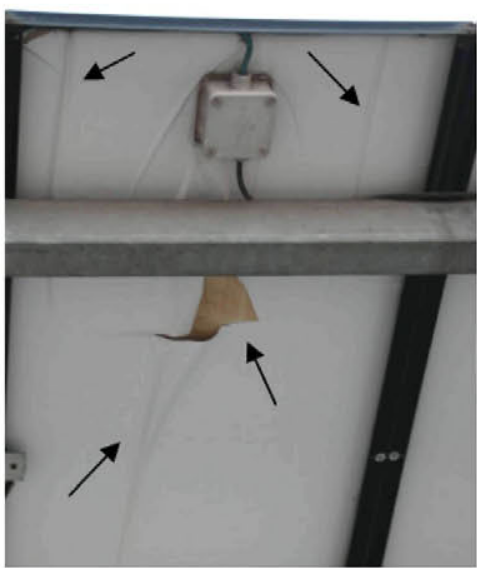

(b)

Figure 3. Visual defects appeared after the first 17 years of operation: backsheet delamination at the outer polyester/polyvinyl fluoride interface.
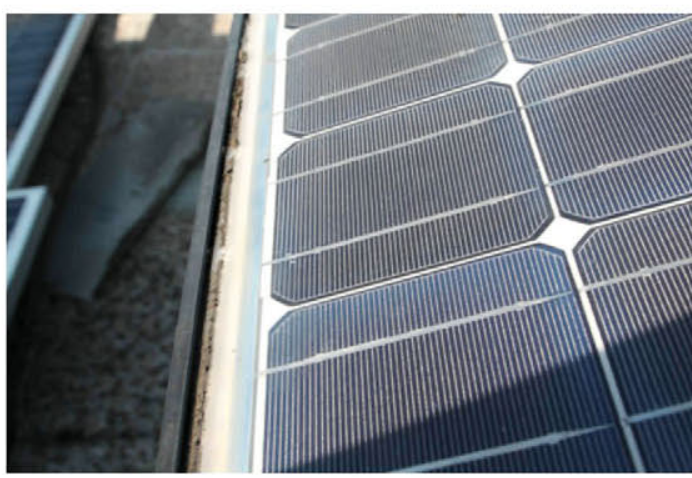

(a)

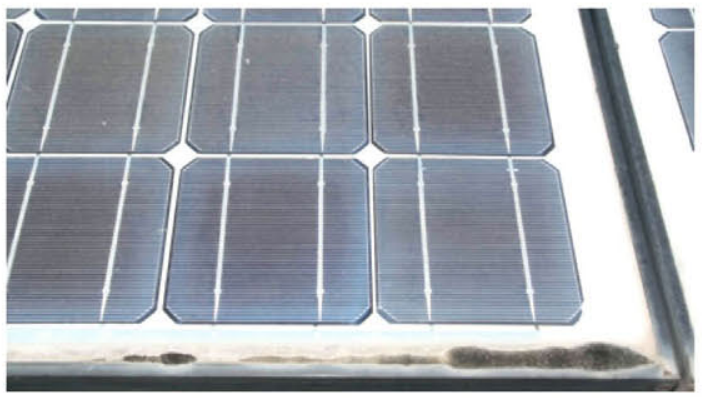

(b)

Figure 4. Visual defects appeared after the first 17 years of operation: (a) cracks and (b) moss in the joint between the laminate and the metallic frame. Solar cells darkening is also clearly visible in this picture.

Despite sometimes being mentioned by other authors, we have not observed other visual defects, such as front delamination (milky pattern) or grid oxidation. The latter suggests that, despite backsheet delamination, the remaining
Table I. Main visual defects found and their incidence in the sample.

\begin{tabular}{lcc}
\hline Defect & Modules affected Percentage (\%) \\
\hline Cracks in the terminal boxes & 6 & 7 \\
$\begin{array}{l}\text { Low-grade backsheet } \\
\text { delamination }\end{array}$ & 42 & 47 \\
High-grade backsheet & 20 & 22 \\
delamination & & \\
Cracks in the frame joint & 33 & 37 \\
Moss in the frame joint & 22 & 24 \\
Solar cells darkening & 75 & 83 \\
\hline
\end{tabular}

PVF/PET sheet is still being able to prevent significant moisture penetration. The relatively dry climate of Madrid can also help to explain this result.

\section{ELECTRICAL PERFORMANCE}

Just 3 days after installation, all the 90 PV modules were tested outdoors by means of an own-made capacitor $I-V$ tracer and two reference PV modules of the same type, previously calibrated at the CIEMAT, for measuring incident irradiance and operation cell temperature. The same was also performed in July 2009. Although a new capacitor $I-V$ tracer was used in this case, it was made using the same design as the one used in the initial measurements. It is worth mentioning that both of them assured capacitor charging times above $30 \mathrm{~ms}$. The reference modules were the same in both cases. They were kept indoors but hanging on a wall and close to a window facing the street, so not in the dark. For this reason, they were 
recalibrated in 2009, again at the CIEMAT. Differences between calibration values have been $-11.2 \%$ in power, $-6.8 \%$ in short-circuit current, $-0.4 \%$ in opencircuit voltage and $-4.4 \%$ in fill factor. All the $I-V$ curves obtained were translated into standard test conditions following the IEC-60891 [17]. Because of the 3 days of initial exposure, we consider that possible light degradation, typical in boron-doped p-type crystalline Si solar cells with oxygen contamination, had already occurred when we measured. Hence, we consider our initial values correspond to the so-called stabilised power. Table II shows the corresponding results in terms of mean and standard deviation values of the main characteristics at standard test conditions. It is worth noting that outdoor exposure has reduced the mean peak power but not enlarged standard deviation values. This suggests homogeneous manufacturing procedures and can be understood as good news, because it implies that mismatch losses in large PV arrays do not significantly increase over time. References [3] and [5] mention a similar result. The mean peak power degradation has been $9.0 \%$ over 17 years, which is often considered as equivalent to $0.53 \%$ per year. The main source of degradation is the shortcircuit current, with a decrease of $8.0 \%$ (or an equivalent to $0.47 \%$ per year), whereas the open-circuit voltage has diminished only a $1.2 \%(0.07 \%$ per year $)$, and the fill factor has remained basically constant. A word of caution is necessary here: because we fully lack in intermediate measurements, we cannot say that degradation has been homogeneous throughout the time, as is suggested by a constant per year ratio. However, other authors have suggested that the degradation of output power in PV modules tends to be linear over time, especially for periods of several years and more [18].

Figures 5-9 show the distribution of the main electrical parameters at the beginning and at the end of the period. All of them followed a normal distribution before the exposition. The short-circuit current and the open-circuit voltage keep their shape after the 17 years of outdoor exposition, whereas the fill factor and the maximum power follow now a Weibull distribution because of the presence of some outliers. It is worth noting that the skewness of the latter curves can translate to increasing mismatching losses [19].

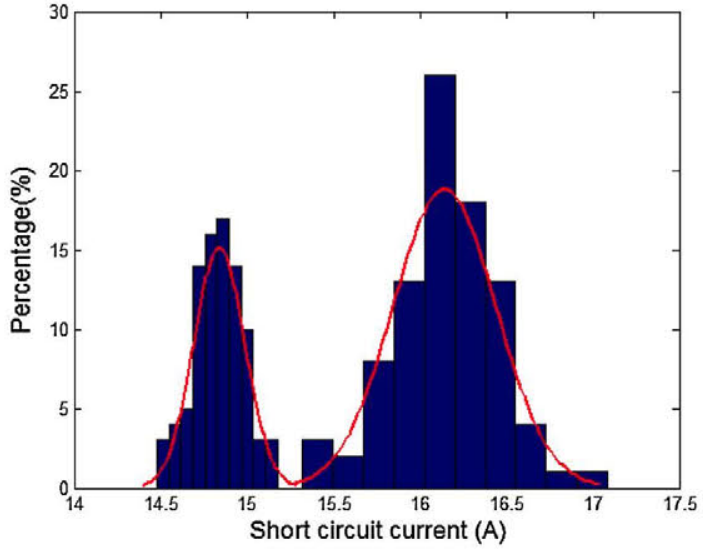

Figure 5. Short-circuit current distribution before (ranging from 15.3 to $17.1 \mathrm{~A}$ ) and after (ranging from 14.5 to $15.2 \mathrm{~A}$ ) the 17 years of outdoor exposition.
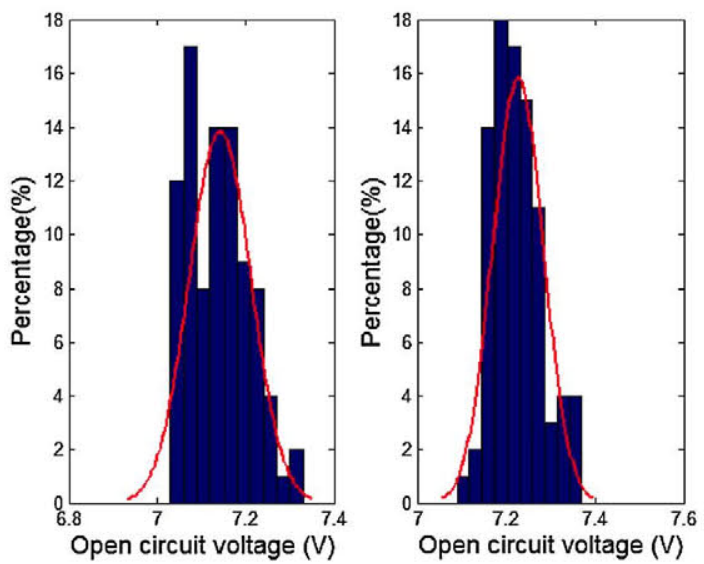

Figure 6. Open-circuit voltage distribution before (right) and after (left) the 17 years of outdoor exposition.

\section{ELECTRICAL INSULATION}

To know the extent at which the aforementioned defects can affect the electrical safety of our installation, we submitted six modules showing low-grade and

Table II. Characteristics at STC of the PV modules, before and after 17 years of exposure.

\begin{tabular}{|c|c|c|c|c|c|c|}
\hline \multirow[b]{2}{*}{ Characteristics at STC } & \multicolumn{2}{|r|}{1992} & \multicolumn{2}{|r|}{2009} & \multicolumn{2}{|c|}{ Degradation } \\
\hline & Mean & Standard deviation & Mean & Standard deviation & Mean $(\%)$ & Per year $(\%)$ \\
\hline Maximum power (W) & 81.1 & 1.06 & 73.8 & 1.50 & -9.0 & -0.53 \\
\hline Short-circuit current $(A)$ & 16.14 & 0.30 & 14.85 & 0.14 & -8.0 & -0.47 \\
\hline Open-circuit voltage (V) & 7.23 & 0.06 & 7.14 & 0.07 & -1.2 & -0.07 \\
\hline Fill factor & 0.696 & 0.01 & 0.696 & 0.01 & 0.1 & 0.00 \\
\hline
\end{tabular}

STC, standard test condition; PV. photovoltaic. 

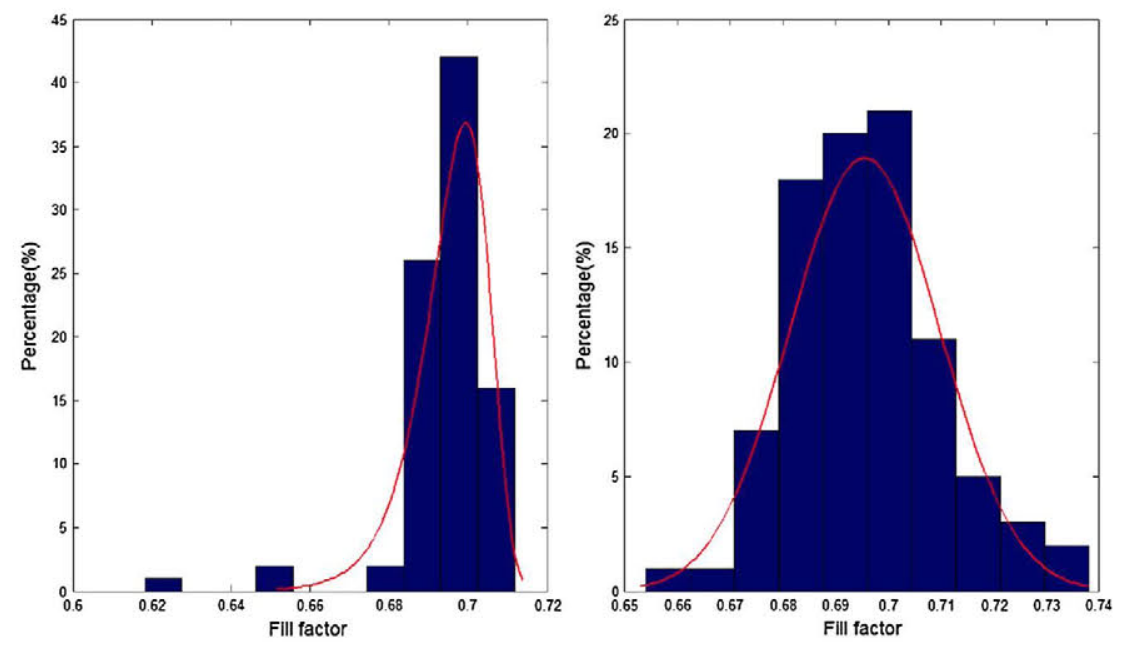

Figure 7. Fill factor distribution before (right) and after (left) the 17 years of outdoor exposition.

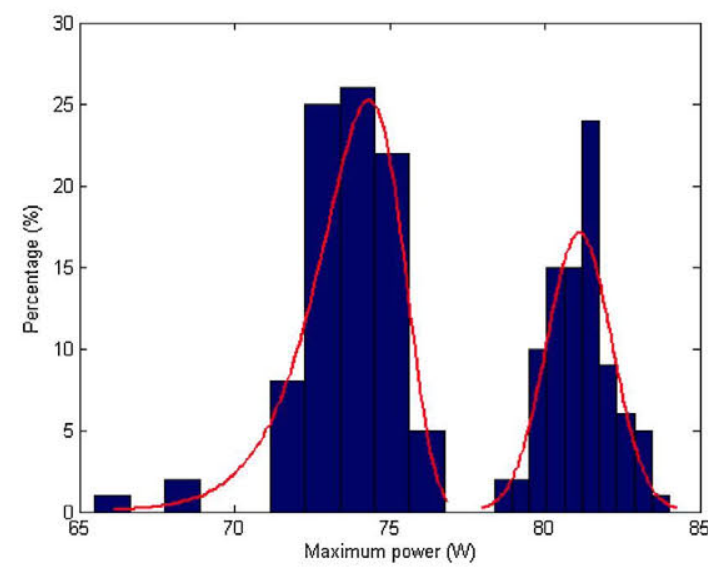

Figure 8. Maximum power distribution before (ranging from 78.4 to 84.0 ) and after (ranging from 65.5 to 76.8 ) the 17 years of outdoor exposition.

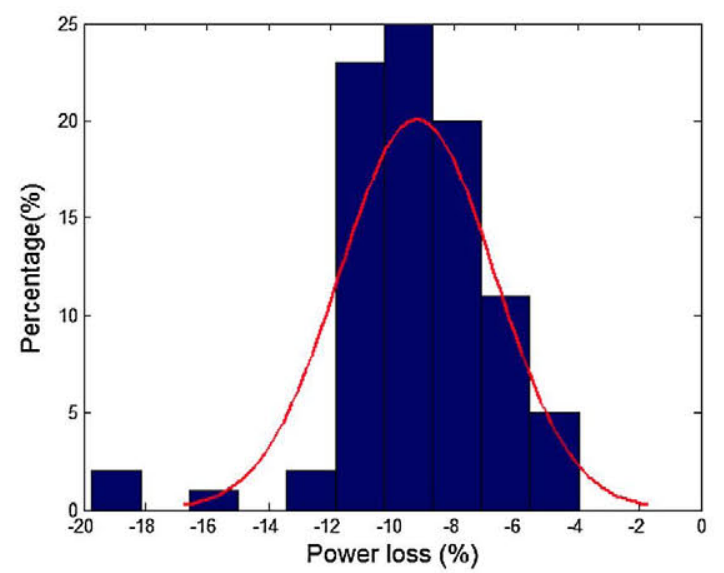

Figure 9. Degradation rate distribution, referred to the power loss. high-grade backsheet delamination to the dielectric withstanding test and to the wet leakage test described in the IEC 61215. Applied voltages have been 1216 and $500 \mathrm{~V}$, respectively. For both tests, the acceptance criterion [11] is that the product of the resulting insulation resistance, $R_{\mathrm{ISO}}$, and the PV module surface, $S$, must be equal to or larger than $40 \mathrm{M} \Omega \cdot \mathrm{m}^{2}$ or $\mathrm{M} \Omega \mathrm{m}^{2}$. Because $S=0.7965 \mathrm{~m}^{2}$, it means $R_{\text {ISO }}$ must be larger than $50.2 \mathrm{M} \Omega$. Figure 10 shows the details of the leakage wet test. Table III shows the tests results. All the modules widely succeeded in passing the tests.

\section{CONCLUSIONS}

The long-term performance of a 7-kWp PV array, made up of $90 \mathrm{PV} \mathrm{Si-x} \mathrm{modules,} \mathrm{after} 17$ years of exposure in Madrid has been presented. The main visual defects are backsheet delamination at the PET/PVF outer interface, antireflective coating degradation and cracks in the terminal boxes and in the joint between the frame and the laminate. However, their impact on performance is rather low: the average peak power degradation is $9 \%$, still within the power warranty offered by the manufacturer; peak power standard deviation remains basically constant; and insulation resistance is several times larger than that required to pass the corresponding IEC 61215 tests successfully. Hence, the PV array is still delivering energy under safe conditions.

\section{ACKNOWLEDGEMENT}

The authors acknowledge the CIEMAT for calibrating the reference modules. 


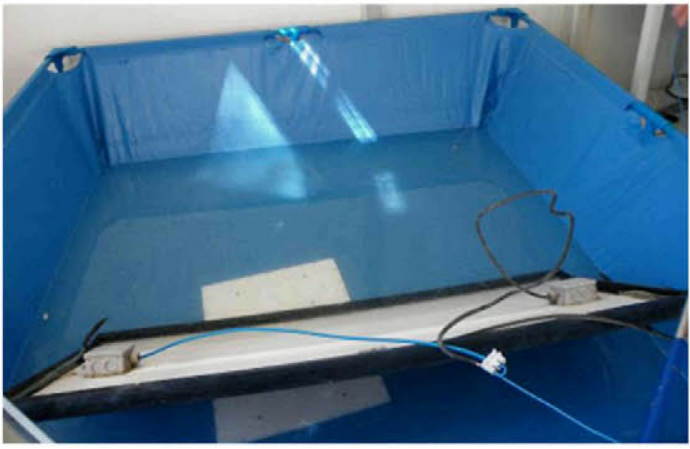

(a)

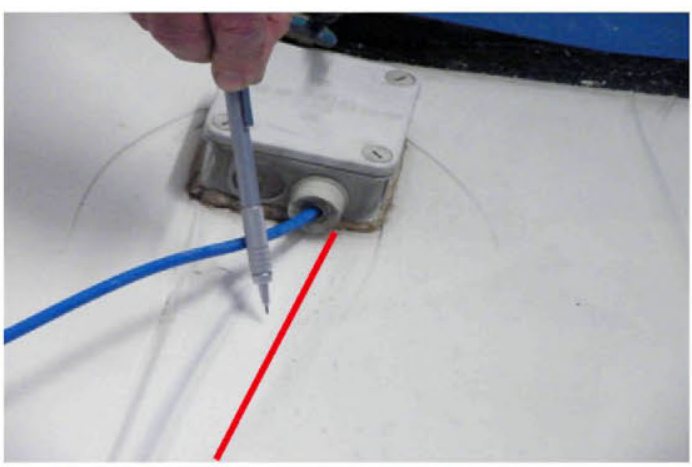

(b)

Figure 10. Wet leakage test. (a) Positive and negative poles are short-circuited. The photovoltaic module is then submersed up to the terminal boxes in a water solution with $656 \Omega \cdot \mathrm{cm}$ or $\Omega \mathrm{cm}$ resistivity, and voltage is applied between the poles and the frame. (b) Detail of the partial submersion: the line indicates the liquid level. The non-submersed part of the module is sprayed with the same water solution.

Table III. Results of the dielectric withstanding and the wet leakage tests for six randomly selected modules.

IEC 61215 test result, $R_{\text {ISO }}(\mathrm{M} \Omega)$

\begin{tabular}{lccc}
\hline $\begin{array}{l}\text { Serial } \\
\text { number }\end{array}$ & $\begin{array}{c}\text { Delamination } \\
\text { grade }\end{array}$ & $\begin{array}{c}\text { Dielectric } \\
\text { withstanding }\end{array}$ & $\begin{array}{c}\text { Wet } \\
\text { leakage }\end{array}$ \\
\hline 030 & High & 2590 & 327 \\
066 & High & 3120 & 379 \\
058 & Low & 2530 & 303 \\
077 & Low & 2830 & 439 \\
088 & Low & 2480 & 427 \\
039 & High & 2210 & 316 \\
\hline
\end{tabular}

IEC. International Electrotechnical Commission.

\section{REFERENCES}

1. King DL, Quintana MA, Kratochvil JA, Elibee DE, Hansen BR. Photovoltaic module performance and durability following long-term field exposure.
Progress in Photovoltaics: Research and Applications 2000; 8(2): 241-256.

2. Dunlop ED, Halton D. The performance of crystalline silicon photovoltaic solar modules after 22 years of continuous outdoor exposure. Progress in Photovoltaics: Research and Applications 2005; 14(1): 53-64. DOI: $10.1002 /$ pip. 627

3. Skoczek A, Sample T, Dunlop ED. The results of performance measurements of field-aged crystalline silicon photovoltaic modules. . Progress in Photovoltaics: Research and Applications 2009; 17: 227-240. DOI: $10.1002 /$ pip. 874

4. Sastry OS, Saurabh S, Shil SK, Kumar R, Kumar A, Bandopadhyay B. Performance analysis of field exposed single crystalline silicon modules. Solar Energy Materials \&Solar Cells, 2010 94: 14631468. DOI: 10.1016/j.solmat.2010.03.035

5. Sánchez-Friera P, Piliougine M, Peláez J, Carretero J, Sidrach de Cardona M. Analysis of degradation mechanisms of crystallines silicon PV modules after 12 years of operation in Southern Europe. Progress in Photovoltaics: Research and Applications 2011 Published online in Wiley Online Library. DOI:10.1002/pip.1083

6. Dhere DH, Pandit MB. Study of delamination in acceleration tested PV modules. Proceedings of the 17th European Photovoltaic Solar Energy Conference, 572-575 2001.

7. Osterwald CR, Pruett J, Moriaty T. Crystalline silicon short-circuit current degradation study: initial results. Proceedings of the 31st IEEE Photovoltaic Specialist Conference, 1335-1338 2005

8. Jorgensen GJ, McMahon TJ. Accelerated and outdoor aging effects on photovoltaic module interfacial adhesion properties. Progress in Photovoltaics: Research and Applications 2008; 16(6): 519-527. DOI: $10.1002 /$ pip.826

9. Vázquez M, Rey-Stolle I. Photovoltaic module reliability model based on filed degradation studies. Progress in Photovoltaics: Research and Applications, 2008; 16(5): 419 433. DOI: 10.1002/pip.825

10. Jorgensen GJ, Terwilleger KM, DelCueto JA, Glick SH, Kempe MD, Pankow JW, Pern FJ, McMahon TJ. Moisture transport, adhesion, and corrosion protection of PV module packaging materials. Solar Energy Materials and Solar Cells 2006; 90: 2739-2775. DOI: $10.1016 /$ j.solmat.2006.04.003

11. International Electrotechnical Commission. Standard IEC 61215: crystalline silicon terrestrial photovoltaic module design qualification and type approval. Sections 10.3 and 10.152006

12. Osterwald CR, McMahon TJ. History of accelerated and qualification testing of terrestrial photovoltaic 
modules. A literature review. Progress in Photovoltaics: Research and Applications 2009; 17(1): 11-33. DOI: $10.1002 / \mathrm{pip} .861$

13. Jordan DC, Kurtz SR. Photovoltaic degradation rates - an analytical review. Progress in Photovoltaics: Research and Applications 2011; 21: 12-29. DOI: $10.1002 / \mathrm{pip} .1182$

14. Osterwald CR, Anderberg A, Rummel S, Ottoson L. Degradation analysis of weathered crystalline-silicon PV modules. Proceedings of the 29st IEEE Photovoltaic Specialist Conference, 1392-1395 2005

15. www.aemet.es/es/elclima/datosclimatologicos

16. Chianese D, Realini A, Cereghetti N, Rezzonico S, Bura E, Friesen G, Bernasconi A. Analysis of weathered c-Si PV modules. 3rd World Conference on Photovoltaic Energy Conversion. 2922-2926 2003

17. International Electrotechnical Commission. Standard IEC 60891: photovoltaic devices-procedures for temperature and irradiance corrections to measured $I-V$ characteristics 2010.

18. Osterwald CR, Adelstein J, Del Cueto JA, Kroposki B, Trudell D, Moriaty T. Comparison of degradation rates of individual modules held at maximum power. Proceedings of the 4th World Conference on PV Energy. 2006.

19. Jordan DC, Wohlgemuth JH, Kurtz SR. Technology and climate trends in PV module degradation. Proceedings of the 27th European Photovoltaic Solar Energy Conference, Frankfurt, Germany 2012. 